\title{
Role conflict and confidentiality in multidisciplinary athlete support programmes
}

\author{
Dave Collins, Phil Moore, David Mitchell, Faith Alpress
}

\begin{abstract}
As medical and scientific staff have increasingly been called upon to provide multidisciplinary support to elite performers the potential for ethical, professional, and legal conflicts has also increased. Although this has been recognised, little guidance has been provided to help resolve such conflicts. This paper identifies key issues in the provision of effective support and specifically addresses the roles of medical and scientific staff and their relations to coaches and performers. An athlete charter is presented that has successfully been used to resolve ethical conflicts and clarify the lines of communication, confidentiality, and responsibility within a national governing body.

(Br F Sports Med 1999;33:208-211)
\end{abstract}

Keywords: support programmes; ethics

With the increased levels of funding available through the World Class Performance Plans, and the increasing use of sports medicine and sports science support by elite athletes, there is a parallel need for support workers to consider the organisational dynamics necessary for most effective work. ${ }^{1}$ Research is only just beginning to consider the various organisational structures of support systems and the pros and cons associated with each system. However, one overriding concern, which has the potential to severely limit programme efficacy, relates to the issue of confidentiality and the extent to which athletes/clients perceive that information given to support staff will be used exclusively for their own individual benefit. Put simply, the issue is this: can the athlete be frank and open with the medical or sports science specialist, or is there a need to guard what is said in order to maintain a positive image with the coach and selectors? Or, as one team player recently put it, "are they one of us or one of them?"

\section{Role conflict in medical support personnel}

Figure 1 presents the basis of role conflict within the support team. Problems may exist regardless of whether the team is multidisciplinary or unidisciplinary in nature, although as later sections will show the problems become increasingly complex as more and more disciplines become involved.

The underlying concern has received some coverage in the sports medicine literature. ${ }^{23}$ However, the lack of consensus among professionals, as shown by both our data and a brief

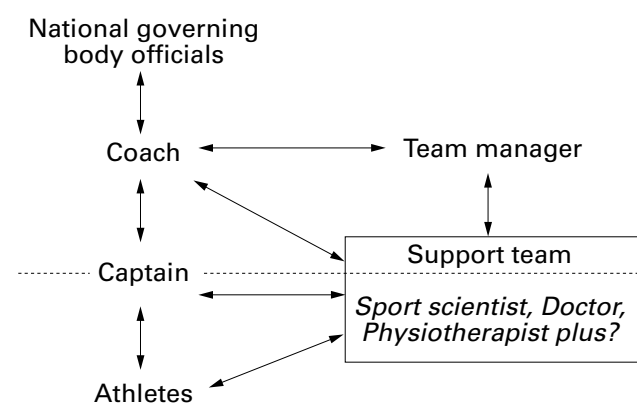

Figure 1 Basis of role conflicts between athletes, officials, and support teams.

anecdotal collection among any group within sport, shows that the clear identification of the "client" is still a concern. Consider fig 1 ; the dashed line represents the "us and them" divide which is of crucial concern to all athletes. Those above the line have power of selection (real or perceived) over those below. Inevitably, and in virtually any sport at any level above the purely recreational, athletes will indulge in high levels of "impression management" in order to protect and/or enhance their position. In fact, research suggests that concerns surrounding this self presentation may well be a larger source of stress for athletes than the competitive environment itself. ${ }^{4}$ Therefore interactions with anyone shown, or even believed, to be above the line will result in limited disclosure and the management of communication. As Leary ${ }^{5}$ points out, this process is neither dishonest nor Machiavellian but rather is an inevitable feature of group dynamics. So if the doctor, physiotherapist, or scientist reports to someone above the line, under virtually any circumstance, athletes will view them as a communication line to coach/selectors and start to manage their interactions accordingly.

Empirical studies consistently show that, from a medical perspective, this impression management almost always takes the form of limiting disclosure about the nature and/or status of injury. In a typical study, Moore and Collins ${ }^{6}$ cite the case of a national squad in which, rather than report injuries to the team physiotherapist, some squad athletes sought treatment from a suitably qualified fellow player. The logic underlying this decision stemmed from the team physiotherapist's "up front" statement that she was responsible to the management for fielding a fit team. As a consequence, players perceived that she was the selector's primary source of information on fitness matters. Players were quite open to investigators about their reasoning: why tell the selectors that you were limited in some way? 
Rather, use the official physiotherapist as another route to confirm your suitability for selection! In fact, physiotherapists who pride themselves on the open communication channels that they enjoy with players may be misguided with certain "streetwise" individuals. Experienced players were clear that they used the physiotherapist as a "naive conduit" through which to strengthen their claim for selection.

Similar problems also apply to other support disciplines. The same investigation ${ }^{6}$ also reported the case of another national team that used a specialist support programme in exercise physiology. When fitness test results were published in the national press in close juxtaposition to the announcement of squad selection, players started to train specifically for the tests and even employed their own fitness advisors, at their own expense, to help them improve their performance on these "obviously" pertinent selection criteria. However, the original support team, clearly perceived as being on the management side of the line, were not consulted by any player, except as part of the impression management process. The message is that, once identified as being on the management side, support professionals will almost inevitably receive a well managed but inherently limited information flow, which may impact on their role efficacy.

An anonymous survey, completed as part of our continuing research projects in this area, discloses that, not surprisingly, medical personnel are well aware of this quandary. Semistructured interviews with five experienced (length of service more than eight years) sport physiotherapists, all currently working with international and/or professional athletes, used hypothetical case studies to probe the ethical dilemmas faced by such staff in their interactions with athletes, coaches, and other officials. All recognised the athlete as the client. "If there are injuries that they don't want the management to know about, I'll discuss it with them....if at the end of the day the player doesn't want me to mention it then I don't" (physiotherapist with international and professional sports teams).

Such attitudes are in keeping with the relevant rules of professional conduct (see the Chartered Society of Physiotherapists rules of professional conduct, rule 3) but all subjects also recognised the pressures applied by coaches, managers, and other officials.

I have a responsibility to the coach....to

the Directors and the management, they

pay my wages...employing me means they

can rest assured that I am acting profes-

sionally...playing people when they are

unfit is not in my vocabulary...responsibil-

ity to the spectators who are paying...so

there are many aspects to this and it weighs heavily sometimes.

(Physiotherapist to a professional sports team)

For others, however, even though they were aware of the ethical requirements of their professional code, the matter was very clear.

Question: Does the player have a right to confidentiality?
No. Because he is part of a team and there are $\mathrm{X}$ other players relying on him.

(Physiotherapist to a professional sports team)

Nor is this matter just a team sport issue. The importance of events may mean that the athlete will ignore advice and compete. This also weighs heavily on the support professional.

Question: Does the importance of an event influence your decisions about an athlete's fitness to compete?

Yes...I'm sure it does, you'd want to hope that it didn't. You just can't help yourself. (Physiotherapist for international level individual sports)

The point of these quotes is to demonstrate what most professionals already recognise to be a problem. It is reassuring to see that certain sporting organisations are addressing this. ${ }^{7}$ However, the quotes and case studies presented here show that simple statements on the need to resolve "conflicts of duty ... in favour of the overriding professional duty to the patient" ${ }^{\prime \prime}$ may be insufficient. Indeed, there may be an overriding concern with patient autonomy. Consider the position of a doctor who removes a player from a competitive environment against his or her will. ${ }^{8}$ Such problems are going to become increasingly common as more sports and athletes are funded to secure support. Professional associations for all support disciplines need to address these issues explicitly in anticipation of the first "loss of earnings" or "restriction of trade" suit. In fact, our research has already uncovered two cases of legal action threatened against the coach and physiotherapist by an irate "dropped" athlete. It can only be a matter of time until such action is taken. Even as this paper is submitted, a legal case has just been brought by a professional athlete against a doctor for assault during a fitness test conducted against the athlete's will. These issues are in urgent need of explicit attention.

Multidisciplinary support teams: codes, mores, and client expectations

The problems outlined in the previous section become even more complex when other scientific and medical disciplines become involved. However, as such multidisciplinary support is recognised as "the way forward" for elite performers, ${ }^{9}$ these complex problems could become an inevitable feature of modern sport. Squads, associations, and teams employ medical personnel, psychologists, physiologists, nutritionists, and biomechanists, together with an increasing array of other specialists including match analysts, lifestyle consultants, and even accountants! What makes things particularly difficult is that each profession may well have a different code of conduct. Even more confusing are the normal expectations and mores of each group. Some actual examples, modified to protect anonymity, will demonstrate these problems.

Firstly, we will look at code of conduct differences. Consider the worst case scenario of a sexual relationship between a coach and an under-age athlete. British Psychological Society guidelines require that the incident is 


\section{The NISA Support Services Charter Your Rights as an Athlete}

The charter sets out your rights as to the confidentiality of information about you. In other words, if you tell one of the support staff something about, say, an injury or some aspect of your performance, the charter is your guarantee that such information will not be passed on to anyone else.

The Squad Doctor, Physiotherapist, Nutritionist and Sport Psychologist will ensure complete confidentiality of information to each individual. In other words, information about you will only be discussed with other support professionals with your express permission. All support staff subscribe to Codes of Conduct which mean that they may not discuss any aspect of your situation with a coach, selector or committee member UNLESS they have your specific permission.

In summary, these support staff will:

- advise you on any medical condition, situation or skill as requested;

- contact other specialists (including your own GP) to ensure effective support but only with your express permission;

- offer educational sessions on various factors of group interest, and;

- advise the national squad coaches on matters of a general nature only, i.e. matters relating to all members of the squad;

The support staff will not:

- give any information, reports or opinions relating to a specific individual without the express permission of that individual, and;

- will play no part in selection, either by sitting on a committee or by passing an opinion to one or more individuals.

Exercise Physiology and Biomechanics support staff will discuss individual data with national squad coaches. Testing completed by these specialists is designed to help the national coaching staff design training and technical programmes. These staff will not however, pass on any information of a confidential nature without your express permission. As with the other support staff they will play no part in selection.

The Association's Medical Officer will conduct medical examinations on behalf of the Association and in preparation for major events such as the Olympic Games. These examinations are designed to confirm your fitness to take part in an event, and the ways in which the results will be used must be explained to you before the examination. S/he will discuss results with national coaching staft and NISA personnel but you have the right to see any reports produced by them.

Figure 2 National Ice Skating Association (NISA) support services charter.

reported, as a legal offence may have been committed. However, the BMA's ethical code still stresses the need for patient confidentiality. What happens when one specialist tells another? Do codes make clear what roles and responsibilities each discipline has with respect to information passed to others?

Secondly, each discipline has its own norms as to role and associated openness of information. Biomechanists and exercise physiologists traditionally report to coaches in order that such data may be used for technical or physical development. Thus each individual's data become public domain, to the extent that results may be openly published or discussed. In contrast, psychologists are required to protect the output of psychometric tests, ensuring that results are effectively interpreted. Furthermore, codes state that these results should not be used for selection purposes. What is the status of medical test data, especially when the same test is administered to all members of a squad? In fact, significant differences in client expectations of these different professions already exist. ${ }^{10}$ It is unfor- tunate but true, however, that these perceptions show little consistency between sports or even between squads of different ages or levels.

In summary, with so many differences between disciplines, how is the athlete to distinguish who says what and to whom? Our research shows that it is the perception that is crucial, so if the athlete is in doubt the medical specialist/scientist is treated as "one of them". The consequences of this labelling are not just alarmist; rather they represent a significant factor that impacts on the effectiveness of the support professional through the limitation and/or distortion of information that she or he will receive.

Avoiding problems: systems, charters, and standards of practice

Given these problems, what steps can be taken to avoid them in the first place? Well firstly, there is a need for all the disciplines, through their professional associations, to negotiate standard systems that recognise the need for confidentiality. To our knowledge, only the Chartered Society of Physiotherapists has a code that specifically addresses these issues (see Chartered Society of Physiotherapists rules of professional conduct, rules 3 and 4) but even this lacks a sufficiently explicit focus on some of the problems highlighted by this paper.

Of course, such issues are very hard to solve at a macro level. Perhaps the best answer, one that can easily be deployed and that stresses the informed consent and autonomy of the client/ patient, is the use of an athlete's charter which can be developed to meet the needs of a specific sport support setting. Figure 2 shows the charter currently used by the National Ice Skating Association (NISA). Note that it presents, as clearly as possible, the scope of data confidentiality and whose interests are being met by each role. Blind evaluation of the system has already shown that athletes are much happier under this regime, and improved uptake of medical services plus more open discussion of problems has already accrued.

With regard to the specific medical provisions, NISA's two doctors serve as both squad and association medical officers, but never at the same time or to the same people. Thus the third author of this paper acts as squad medical officer (with skater needs paramount) for speed skating, while conducting medical checks on figure and dance skaters before events (association needs take precedence). The other doctor acts as the mirror of these roles. Skaters are clearly told in which role the medical officer is acting, a distinction that is aided by the clear delineation of role by sport discipline that covers the other support professionals who interact with the squad.

\section{Summary}

Despite a widespread recognition of the problem, from a basic level at least, evidence shows that confidentiality issues are far from being covered effectively. In fact, with the added complexities that multidisciplinary support may bring, these issues require early resolution if such programmes are to be optimally 
effective. Although broader generic solutions will require much effort, simple procedures can be effected which counter the "us and them" situations that typify lack of clarity over confidentiality. The use of athlete charters, which detail roles and athlete expectancies, is offered to the sports medicine and sports science communities as a basis for future support programmes and larger scale development of national systems.

Contributors: D C wrote the paper and developed the ideas in association with the other authors. He acts as guarantor for the content of the paper. P M was the primary investigator who collected the data on which the paper's arguments are built. He was assisted by Joe Tomlinson who completed aspects of the data collection as part of a taught course requirement. D M and F A, respectively the doctor and physiotherapist to the National Ice Skating Association, contributed to the discussion and the Skating Association, contributed to the
development of the NISA athlete's charter.
1 Moore PM, Collins DJ, Burwitz L, et al. Identification and development of talent in selected UK sports. I Sports Sci 1998;16:42.

2 Payne SDW. Medicine, sport and the law. Oxford: Blackwell Scientific Publications, 1990.

3 Sim J. Sports medicine: some ethical issues. Br f Sports Med 1993;27:95-100.

4 James BD, Collins, DJ. Self presentational aspects of pre-competitive anxiety. Fournal of Sport and Exercise Psychology 1997;15:17-35.

5 Leary MR. Self presentation processes in exercise and sport. Fournal of Sport and Exercise Psychology 1994;14:339-51.

6 Moore PM, Collins DJ. Role conflict in team sports settings. In Steinberg H, Annett J, eds. Workshop report on teamwork. Leicester: British Psychological Society, 1996.

7 Collins DJ. Presentation to BOA Psychology Advisory Group Meeting, Edinburgh, June 1998.

8 British Medical Association. Sport and exercise medicine: policy and provision. London: BMA Board of Science and Education, 1996.

9 Rowell S. Sport science support programme review. Leeds: National Coaching Foundation, 1998

10 Abbott A, Collins DJ, Moore PM, et al. Consumer expectations of sport psychology. F Sports Sci 1998:16:68-9.

\section{Take home message}

Depending on the levels of confidentiality that exist, or are perceived to exist, in a team/squad setting, athletes will vary in the openness of their communication with medical and support personnel. Specifically, the perception of a support provider's "executive status" will determine whether that individual is seen as a genuine support or a means of covert communication to enhance chances of selection. Consequently, clear statements as to who you perceive as your primary client will enhance or potentially limit your efficacy in interactions with athletes.

\section{Commentary}

This paper is highly relevant at a time when lottery funded World Class Performance Plan athletes become, effectively, professionals employed by national governing bodies. Debate on confidentiality issues and exactly who is the doctor's "client" are important and rarely produce consensus among team doctors.

The scenario of restriction of trade suits and assault cases filled me with anxiety which will be shared by all team doctors. I would hope to see a medicolegal commentary on these points in a subsequent issue of this journal.

The athlete who nurses an injury and wishes to keep this information from management will be familiar to all team doctors. By defining and separating the roles of squad doctor and association medical officer, the NISA system enables the athlete to talk confidentially to the team doctor and to undergo treatment. On the negative side, the "fitness to compete" medical is canted out by a doctor who has no privileged medical information on the competitor.

This is an excellent paper which raises awareness of issues common to all disciplines. All national governing bodies will no doubt debate these issues and I suspect that many will produce their own sports specific athletes' charters.

CHRIS JARVIS

Boscastle, Cornwall 